\title{
Team science in vaccine development in developing countries
}

Volume 4 Issue 3 - 2017

Keywords: team science, vaccines, rotavirus, low-income countries, india

Abbreviations: PATH, program for appropriate technology for health

The successful development of Rotavirus 116E Vaccine by an Indian company Bharat Biotechnology International (BBI) through multiple international public-private partnership (PPP) is a hallmark to the success of "Team Science". As reported in the Lancet ${ }^{1}$ the effort culminated in the successful safety and efficacy testing in Phase III clinical trials of Rotavirus $116 \mathrm{E}$ in low income country settings. ${ }^{2}$ Team Science is a collaborative, multi-disciplinary approach involving coming together of scientific partners hitherto working in isolation towards a shared goal or purpose. ${ }^{3}$ The Rotavirus $116 \mathrm{E}$ vaccine development effort involved the coming together of 13 partners with BBI playing a central role. The effort involved generous funding through the Bill and Melinda Gates Foundation (through PATH) and Department of Biotechnology, Government of India with technical assistance from US Centre for Disease Control and Prevention, National Institute of Allergy and Infectious Diseases, Stanford University, and Indian Institute of Science.

The success of this initiative has removed a number of obstacles for the development of a safe, efficacious and cheap vaccine in lowincome countries. The current commercial vaccines cost around US\$200 in the USA and US\$20 in the Latin American. The GAVI alliance provides substantial subsidies for vaccine to be made available under US\$0.45-1.00 to low-income countries. However, the current commercial vaccines are less immunogenic in India and other low-income countries. Moreover, these vaccines have not been clinically tested in low-income countries. On the contrary, the Rotavirus $116 \mathrm{E}$ vaccine has been found to be safe and as efficacious in clinical vaccines conducted in India. ${ }^{2}$

The success of this "Team Science" initiative has helped many Indian groups develop substantial technical expertise. For example, BBI has through this endeavour developed technological, regulatory and manufacturing expertise leading to the licensure and manufacture of several licensed vaccines that are being used in many low-income countries.

Hence, "Team Science" provides a collaborative approach that benefits not only the individual collaborators but also help in the development of social capital. Such initiatives will help reduce not only the disease burden but also the economic burden of vaccines in

\author{
Srinivas Garlapati \\ Department of Health Care Administration, Canadore College, \\ Canada
}

Correspondence: Srinivas Garlapati, Department of Health Care Administration, Canadore College, 930 Progress Avenue, Scarborough, ON, MIG 3T5, Canada, Email Srinivas.garlapati@Dal.Ca

Received: May 18, 2017 | Published: June 05, 2017

low-income countries. Team Science requires substantial cultural shift that should be inculcated among researchers from very early stage of their careers. To this effect the author would refer the readers to "Collaboration and Team Science: A Field Guide" ${ }^{3}$ for understanding the nuances of "Team Science".

\section{Acknowledgments}

None.

\section{Conflicts of interest}

Author declares there are no conflicts of interest.

\section{Funding}

None.

\section{References}

1. Bhan M, Glass R, Ella K, et al. Team science and the creation of a novel rotavirus vaccine in India: a new framework for vaccine development. Lancet . 2014;383(9935):2180-2183.

2. Bhandari N, Rongsen-Chandola T, Bavdekar A, et al. Efficacy of a monovalent human-bovine $(116 \mathrm{E})$ rotavirus vaccine in Indian infants: a randomised, double-blind, placebo-controlled trial. Lancet. 2014; 383(9935): 2136-2143.

3. Michelle LB, Howard G, Levine-Finley S. Collaboration and Team Science: A Field Guide. (1st edn), National Institute of Health, Bethesda, USA. 2010. 